\title{
PERENCANAAN METODE PELAKSANAAN DAN RENCANA ANGGARAN BIAYA REKONSTRUKSI JPO PASAR MINGGU
}

\section{(Planning Method of Implementation and Budget Plan Cost Reconstruction JPO At Pasar Minggu)}

\author{
Naomi Oktriani Br Damanik ${ }^{1}$, Kusno Adi Sambowo ${ }^{2}$ \\ ${ }^{1} \mathrm{PT}$. Grid Solution Indonesia \\ ${ }^{2}$ Program Studi Teknik Sipil Universitas Pancasila \\ E-mail: nomidmk@yahoo.com
}

\begin{abstract}
ABSTRAK
Jembatan penyeberangan orang yang berada di pasar minggu merupakan penghubung antara stasiun kereta dengan pusat perbelanjaan yang berada di seberangnya. Kegiatan rekonstruksi jembatan yang telah rubuh dimulai dengan identifikasi masalah dan penelitian, selanjutnya memilih metode yang paling tepat untuk digunakan pada proses rekonstruksi,dan menghitung biaya untuk rekonstruksi jembatan tersebut. Dari hasil penelitian dapat diketahui bahwa jembatan direkonstruksi dengan metode perkuatan dimana struktur jembatan yang ada diperkuat dengan metode perancah dan peluncuran sehingga jembatan tersebut kembali menjadi layak untuk digunakan,dan biaya yang dibutuhkan untuk merekonstruksi jembatan tersebut sebesar Rp 1.213.239.230.
\end{abstract}

Kata Kunci : Jembatan penyeberangan orang, rangka baja, metode pelaksanaan, biaya

\begin{abstract}
The crossing bridge at Pasar Minggu is the link between the train station and the shopping center opposite. The reconstruction of the collapsed bridge starts with problem identification and research, then chooses the most appropriate method to use in the reconstruction process, and calculates the cost for the reconstruction of the bridge. From the research results it can be seen that the bridge is reconstructed by retrofitting method where the existing bridge structure is reinforced by the method of scaffolding and launching, so that the bridge is again become feasible to be used, and the cost required to reconstruct the bridge is $R p$ 1.213.239.230.
\end{abstract}

Keywords : Crossing bridge of people, steel frame, method of implementation, cost 


\section{PENDAHULUAN}

Peningkatan kepadatan transportasi memerlukan penanganan secara menyeluruh, mengingat bahwa transportasi timbul karena adanya perpindahan manusia dan barang dari satu tempat ke tempat lain, meningkatnya perpindahan tersebut dituntut penyediaan fasilitas penunjang guna membantu laju perpindahan manusia maupun barang agar memenuhi ketentuan, kecepatan dan keselamatan, dalam kondisi perkotaan yang selalu berkembang mobilitas manusia dari tempat ketempat lain adalah tidak lepas kegiatan yang harus dilakukan menyeberang jalan, dimana pejalan kaki merupakan salah satu komponen lalu lintas yang sangat penting yang harus di jaga keselamatanya.

Jembatan penyeberangan jalan dipasang apabila diharuskan tidak ada pertemuan sebidang antara arus pejalan kaki dengan arus lalu lintas agar pejalan kaki mau untuk menggunakan jembatan penyeberangan harus dijamin keamanan dan jarak berjalan tidak terlalu bertambah jauh, serta jembatan penyeberangan dirancang dengan kriteria tertentu selain dapat memenuhi dari segi fungsi, kemanfaatan, stardar konstruksi, keamanan, kenyamanan juga faktor lain yang berhubungan dengan keselamatan pengguna maupun kelengkapan lainya atau jembatan juga sebagai street furniture di lokasi jalan tersebut.

Sibuknya jalan raya di kota, menjadikan kota tersebut tidak nyaman bagi pejalan kaki, karena dimana- mana jalan tersebut dipenuhi kendaraan bermotor dan tidak memberi kesempatan sedikitpun pada pejalan kaki. Sedangkan masih rendahnya kesadaran masyarakat memanfaatkan fasilitas penyeberangan yang ada sebagai sarana penyeberangan aman, nyaman.

Jembatan penyeberangan mempunyai fungsi besar sebagai sarana perpindahan moda transportasi pejalan kaki yang akan menyeberang, disini peranan jembatan penyeberangan sangat penting bagi penyeberang disekitar daerah yang rawan kecelakaan lalu-lintas ( fast moving ). Oleh karena itu jika sarana Zebra cross sudah tidak dapat mengatasi, peranan jembatan penyeberangan dapat menggantikannya sebagai alternatif keselamatan dalam menghindari kecelakaan lalu-lintas dan kemacetan jalan.

Selain fungsi pokok, fungsi dan peranan sekunder dari jembatan penyeberangan yaitu sebagai elemen / bagian dari street furniture dan pelengkap kota yang keberadaanya harus tepat dan berfungsi dengan baik. Melalui sarana jalan diharapkan dapat meningkatkan tingkat perekonomian dan kesejahteraan masyarakat dan memberi kemudahan bagi masyarakat.

Seperti halnya di kota Jakarta Selatan tepatnya di daerah stasiun Pasar Minggu yang berseberangan dengan pusat perbelanjaan maka fasilitas pejalan kaki seperti jembatan penyeberangan sangat dibutuhkan. Sebelumnya telah dibangun jembatan penyeberangan di daerah ini namun pada 24 September 2016 struktur atas jembatan penyeberangan tersebut ambruk dan hingga saat ini belum diperbaiki kembali. Jembatan yang sebelumnya dibangun adalah jembatan penyeberangan orang jenis konvensional,tanpa tambahan fasilitas bagi kaum disabilitas. Oleh karena itu perlu dilakukan perencanaan ulang yang baik dan benar untuk merekonstruksi jembatan penyeberangan tersebut sehingga dapat digunakan oleh masyarakat normal dan kaum disabilitas.

\section{JEMBATAN SECARA UMUM}

Jembatan merupakan suatu konstruksi yang berfungsi untuk meneruskan jalan melalui suatu rintangan yang berada lebih rendah, dimana rintangan ini biasanya jalan berupa lain yaitu jalan air atau jalan lalu lintas biasa (Struyk, 1995). Jembatan memiliki arti penting bagi setiap orang, dengan tingkat kepentingan yang berbeda-beda tiap orangnya (Supriyadi, 2000). Menurut Bambang Supriyadi, jembatan bukan hanya kontruksi yang berfungsi menghubungkan suatu tempat ke tempat lain akibat terhalangnya suatu rintangan, namun jembatan merupakan suatu sistem transportasi, jika jembatan runtuh maka sistem akan lumpuh.

Jembatan penyeberangan orang atau yang biasa disingkat JPO adalah fasilitas pejalan kaki untuk menyeberangi jalan yang ramai dan lebar, atau menyeberang jalan tol dengan menggunakan jembatan, sehingga orang dan lalu lintas kendaraan dipisah secara fisik. Jembatan penyeberangan adalah fasilitas penyeberangan pejalan kaki tak sebidang.

Fasilitas ini memisahkan arus penyeberang jalan dengan arus kendaraan sehingga konflik antara kedua unsur tersebut tidak terjadi. Fasilitas ini merupakan bentuk fasilitas penyeberangan pejalan kaki yang paling aman dibandingkan dengan fasilitas penyeberangan lainnya. Jembatan penyeberangan termasuk unsur jaringan transportasi perkotaan. Sesuai dengan defenisi yang tercantum dalam Tata Cara Perencanaan Jembatan Penyeberangan Untuk Pejalan Kaki Di Perkotaan, Departemen $P U$, jembatan penyeberangan pejalan kaki adalah jembatan yang hanya diperuntukkan bagi lalu lintas pejalan kaki yang melintas di atas jalan raya atau jalan kereta api. 
Pembangunan jembatan penyeberangan disarankan memenuhi ketentuan sebagai berikut :

a. Bila fasilitas penyeberangan dengan menggunakan zebra cross dan pelikan cross sudah mengganggu lalu lintas yang ada.

b. Pada ruas jalan dimana frekuensi terjadinya kecelakaan yang melibatkan pejalan kaki cukup tinggi.

c. Pada ruas jalan yang mempunyai arus Ialu lintas dan arus pejalan kaki yang tinggi.

\section{Komponen Jembatan Rangka Baja dan Fungsinya}

a. Lantai Kendaraan Jembatan ini berfungsi untuk lalu lintas kereta api. Sehingga lantai kendaraannya berupa rel kereta api yang terbuat dari baja dan bantalan rel yang terbuat dari kayu.

\section{b. Balok Memanjang}

Balok memanjang berfungsi untuk menyalurkan beban-beban lantai kendaraan (beban mati dan beban hidup) ke balok melintang. Pada jembatan ini, bantalan relnya diikatkan/diletakkan langsung pada balok memanjangnya. Jembatan ini memiliki dua gelagar memanjang yang terbuat dari profil WF.

\section{c. Balok Melintang}

Balok melintang memikul beban-beban melalui gelagar memanjang dan menyalurkannya ke rangka batang. Pada jembatan ini, gelagar melintang tersebut terbuat dari plate girder, yakni susunan plat sedemikian rupa sehingga membentuk profil baru (pada umumnya berbentuk I). Gelagar melintang tersebut diletakkan segaris dengan batang vertikal rangka batang induk.

\section{d. Ikatan Angin}

Ikatan angin berfungsi untuk menyalurkan gaya angin kepada perletakan. Beban angin tersebut bekerja di titik-titik simpul. Berhubung jembatan ini adalah jembatan rangka terbuka, maka semua beban angin tersebut disalurkan ke titiktitik simpul bagian bawah. Jembatan ini memiliki ikatan angin yang terbuat dari profil siku dan dibuat berbentuk belah ketupat.

\section{e. Ikatan Tumbuk}

Ikatan tumbuk berfungsi sebagai pengaku untuk mengurangi lenturan pada gelagar memanjang akibat gaya horisontal yang diakibatkan oleh roda kereta api. Ikatan tumbuk pada jembatan ini terbuat dari baja siku yang diletakkan diantara gelagar memanjang membentuk ikatan silang. f. Rangka Batang Induk

i. Rangka diagonal

Rangka batang diagonal pada jembatan ini terbuat dari baja double canal. Masingmasing baja canal tersebut disambung dengan menggunakan plat dan paku keling di 4 titik dalam satu bentang. Plat dan paku keling tersebut berfungsi agar beban aksial yang bekerja pada batang tersebut terbagi dua merata ke masingmasing baja canal.

ii. Rangka vertikal

Rangka vertikal pada jembatan ini terbuat dari baja WF dengan penebalan pada bagian badan profil dengan menggunakan plat.

iii. Rangka tepi atas

Rangka tepi atas pada jembatan ini terbuat dari baja double canal. Pada saat jembatan tersebut menerima beban, batang tepi atas menerima gaya aksial tekan. Gaya aksial tekan tersebut paling besar terletak pada tengah bentang jembatan. Sehingga pada rangka tepi atas bagian tengah bentang dibuat penebalan profil.

iv. Rangka tepi bawah

Rangka tepi bawah dari jembatan ini terbuat dari baja double canal. Karena rangka tepi bawah menerima gaya tarik saja, sehingga tidak dibutuhkan penebalan profil sama seperti rangka tepi atas.

\section{g. Pengaku / Stifner}

Pada jembatan rangka terbuka tidak memiliki ikatan angin atas. Portal akhir dari jembatan rangka terbuka dibentuk oleh batang tepi rangka batang induk dengan balok melintang. Dengan demikian, hubungan antara rangka vertikal dengan balok melintang harus dibuat sekaku mungkin. Untuk itu dibuat pengaku/stiffner untuk menjaga kekakuan melintang dari jembatan tersebut. Pengaku pada jembatan ini tersusun dari plat dan profil baja double siku.

\section{h. Sambungan}

Sambungan berfungsi sebagai penyaluran beban dari batang yang satu ke batang yang lain. Secara umum, jembatan ini menggunakan plat dan paku keling sebagai sambungannya.

Penggunaan plat sebagai sambungan dapat mengakibatkan sobek pada plat (akibat gaya tarik) dan tekuk (akibat gaya tekan), sedangkan paku keling atau baut dapat mengakibatkan putus pada baut (akibat gaya tekan atau tarik). 
i. Sambungan ikatan angin dan ikatan tumbuk

Sambungan ikatan angin terdiri dari plat dan paku keling. Sedangkan sambungan ikatan tumbuk terditi dari baja siku dan paku keling.

ii. Sambungan balok memanjang-balok melintang

Terdiri dari baja siku dan paku keling dimana sisi yang satu dari baja siku disambung pada sisi badan profil balok memanjang dan sisi yang lain dari baja siku tersebut disambung ke sisi badan profil balok melintang.

iii. Sambungan balok melintang-rangka batang utama

Menggunakan baja siku dan paku keling dimana sisi yang satu dari baja siku disambung ke badan dari balok melintang dan sisi yang lain disambung ke batang vertikal dari rangka batang utama.

iv. Sambungan rangka vertikal-rangka tepi bawah

Sambungan ini menggunakan profil double siku dan paku keling dimana profil doublu siku tersebut diletakkan di luar dari profil rangka tepi bawah (double canal) dan kemudian disambung dengan paku keling sampai ke rangka vertikal.

\section{v.Sambungan titik simpul atas}

Pada sambungan titik simpul atas, batang-batang yang disambung adalah batang diagonal, batang vertikal, dan batang tepi atas. Secara keseluruhan batang-batang tersebut disambung dengan menggunakan plat dan paku keling. Namun pada batang diagonal dan batang tepi atas (menggunakan profil double canal) menggunakan profil baja siku dan paku keling juga sebagai sambungan ke plat simpul. Profil baja siku tersebut digunakan untuk menyalurkan yang berada pada flens dari batang diagonal tersebut.

\section{j. Perletakan}

Perletakan berfungsi untuk menyalurkan beban jembatan keseluruhan ke pilar atau kepala jembatan. Perletakan yang ada harus sesuai antara perencanaan dengan kenyataan di lapangan. Apabila pelaksanaan perletakan tidak sesuai dengan perencanaan maka pada rangka utama akan timbul gaya-gaya ekstra yang cukup besar. Gaya-gaya ekstra tersebut mengakibatkan penambahan atau pengurangan gaya-gaya batang. Bahkan mungkin saya batang tarik berubah menjadi batang tekan atau sebaliknya.
Pada jembatan ini, menggunakan sendi-rol sebagai perletakan yang terbuat dari baja.

- Perletakan rol

- Perletakan sendi

\section{RENCANA ANGGARAN BIAYA}

Menurut Sastraatmadja (1991), penaksiran anggaran biaya adalah proses perhitungan volume pekerjaan, harga dari berbagai macam bahan dan pekerjaan yang akan terjadi pada suatu konstruksi. Karena taksiran dibuat sebelum dimulainya pembangunan maka jumlah ongkos yang diperoleh ialah taksiran bukan biaya sebenarnya (actual cost).

Secara umum proses analisa harga satuan pekerjaan dengan metode Lapangan/Kontraktor adalah sebagai berikut :

1. Membuat Daftar Harga Satuan Material dan Daftar Harga Satuan Upah.

2. Menghitung harga satuan bahan dengan cara ; perkalian antara harga satuan bahan dengan nilai koefisien bahan.

3. Menghitung harga satuan upah kerja dengan cara ; perkalian antara harga satuan upah dengan nilai koefisien upah tenaga kerja.

4. Harga satuan pekerjaan $=$ volume $x$ (jumlah bahan + jumlah upah tenaga kerja).

\section{Metode Pelaksanaan Pembangunan Konstruksi Jembatan}

Bagian-bagian struktur utama dari konstruksi jembatan adalah struktur pondasi, struktur abutment, struktur pilar, struktur lantai jembatan, struktur kabel, dan struktur oprit. Bagian metoda konstruksi terpenting dalam konstruksi jembatan adalah proses erection lantai jembatan, dimana banyak metoda dimungkinkan untuk melakukan erection tersebut.

Adapun metoda konstruksi terpenting dalam konstruksi jembatan juga sangat bervariasi dan sangat ditentukan oleh banyak pertimbangan, antara lain:

- Kondisi medan,

- Tipe alat yang telah dimiliki,

- Kondisi akses menuju ke lokasi proyek,

- Pertimbangan lalu lintas lama,

- Tipe material dan struktur jembatan yang digunakan, apakah baja atau beton.

- Pertimbangan waktu pelaksanaan Berikut adalah beberapa tipe metode pemasangan jembatan yang umumnya digunakan untuk berbagai konstruksi jembatan : 
a. Sistem Perancah

b. Sistem Servis Crane

c. Sistem Launching Truss

d. Sistem Penggunaan Counter Weight dan Link Set

e. Sistem Launching Gantry

f. Sistem Traveller atau Heavy Gantry

\section{PENGUMPULAN DATA}

Pengumpulan data dilakukan untuk memperoleh informasi yang dibutuhkan dalam rangka mencapai tujuan penelitian. Sebelum melakukan penelitian, seorang peneliti biasanya telah memiliki dugaan berdasarkan teori yang ia gunakan, dugaan tersebut disebut dengan hipotesis.Untuk membuktikan hipotesis secara empiris, seorang peneliti membutuhkan pengumpulan data untuk diteliti secara lebih mendalam.

Penulisan skripsi ini adalah melakukan penelitian tentang metode pelaksanaan yang paling tepat untuk dilaksanakan dan perhitungan rencana anggaran biaya pembangunan Jembatan Penyeberangan Orang di Stasiun Pasar Minggu. Struktur JPO di Stasiun Pasar Minggu sudah ada sebelumnya,tetapi mengalami kerusakan sehingga penulis ingin meneliti metode pelaksanaan apa yang paling tepat untuk dilaksanakan dan berapa anggaran biaya yang dibutuhkan, mengingat JPO tersebut sangat dibutuhkan oleh pengguna jalan kaki.

Penelitian akan dilakukan dengan dua tahapan, yaitu :

1. Pengambilan data eksisting JPO di Stasiun Pasar Minggu dari Dinas Bina Marga Provinsi DKI untuk mendapatkan data primer. Data primer berupa spesifikasi jembatan dan gambar rencana konstruksi JPO yang akan digunakan untuk rekonstruksi.

2. Dengan menganalisa data yang didapat dengan literatur tentang metode pelaksanaan dan rencana anggaran biaya untuk mendapatkan data sekunder.

Tahap pelaksanaan penelitian dan penulisan yang dilakukan meliputi :

a. Melakukan studi literatur untuk mendapatkan tinjauan pustaka

b. Membuat model sistem pengumpulan data

c. Mengumpulkan data

d. Menganalisa data yang didapatkan

Proses penelitian metode pelaksanaan konstruksi dan rencana anggaran biaya JPO di Stasiun Pasar Minggu dapat dilihat pada bagan berikut.

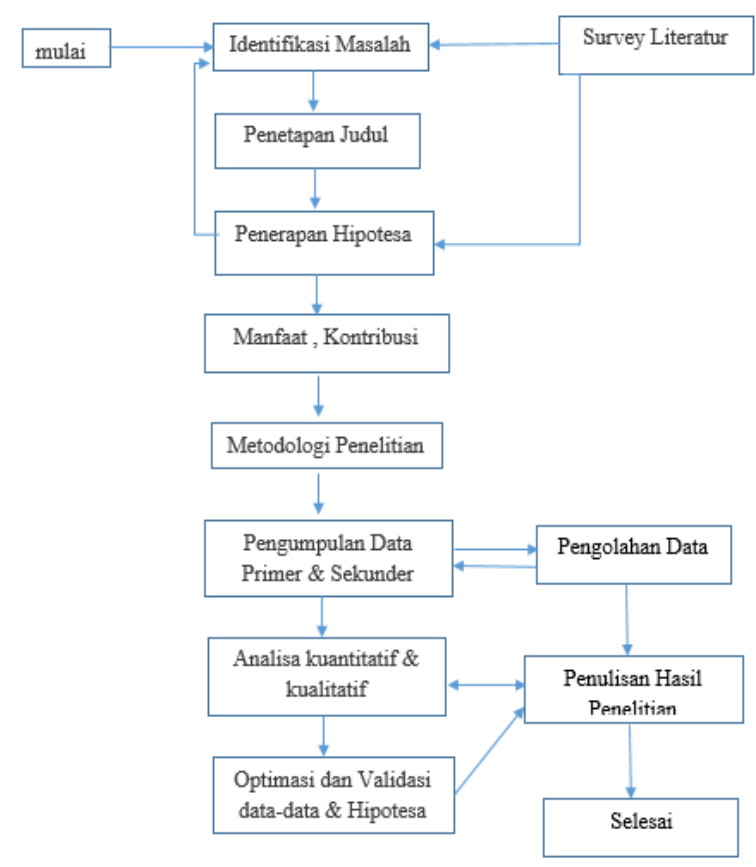

Gambar 1. Bagan Alir Penelitian

\section{PEMBAHASAN}

Jembatan rangka baja adalah struktur jembatan yang terdiri dari rangkaian batang batang baja yang dihubungkan satu dengan yang lain. Beban atau muatan yang dipikul oleh struktur ini akan diuraikan dan disalurkan kepada batang batang baja struktur tersebut, sebagai gaya gaya tekan dan tarik, melalui titik titik pertemuan batang (Titik Buhul). Gaya gaya eksentrisitas yang dapat menimbulkan momen sekunder selalu dihindari. Oleh karena itu garis netral tiap tiap batang yang bertemu pada titik buhul harus saling berpotongan pada satu titik saja, untuk menghindari timbulnya momen sekunder.

Dengan demikian ada hal hal penting yang perlu diperhatikan pada konstruksi rangka baja yaitu :

- Mutu dan dimensi tiap tiap batang harus kuat menahan gaya yang timbul. Batang batang dalam keadaan tidak rusak/bengkok dan sebagainya. Oleh karena itu batang batang rangka jembatan harus dijaga selama pengangkutan, penyimpanan, dan pemasangan.

- Kekuatan pelat penyambung harus lebih besar daripada batang yang disambung (Struktur sambungan harus lebih kuat dari batang utuh).

- Untuk mencegah terjadinya eksentrisitas gaya yang dapat menyebabkan momen sekunder, maka garis netral tiap batang yang bertemu harus berpotongan melalui satu titik (harus merencanakan bentuk pelat buhul yang tepat). Pelat buhul yang paling ujung, baik pelat buhul bawah maupun atas, Biasanya panjangnya dilebihi, untuk 
keperluan penyambungan dengan linking steel bila diperlukan.

Kondisi jembatan penyeberangan eksisting dapat dilihat dari gambar dibawah:

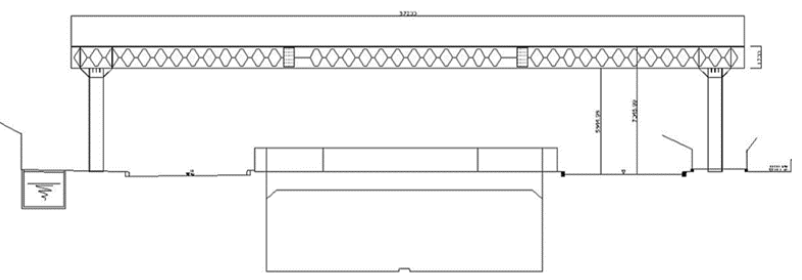

Gambar 2. Tampak Depan Struktur Eksisting JPO di Stasiun Pasar Minggu

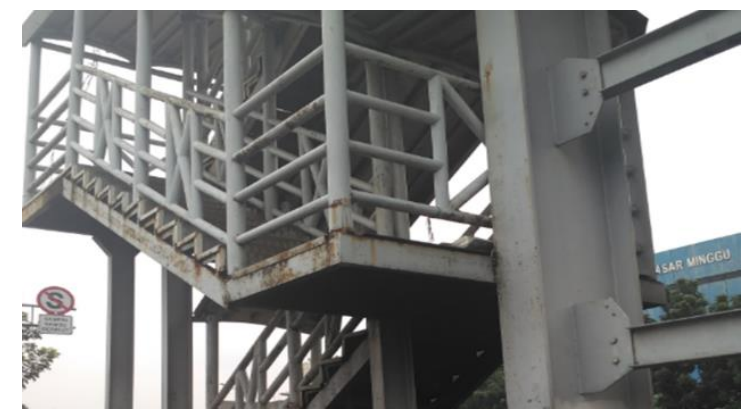

Gambar 3.Tangga dan Hand Railing Eksisting Jembatan Penyeberangan Orang di Stasiun Pasar Minggu

Untuk mengembalikan fungsi jembatan penyeberangan orang di Stasiun Pasar Minggu yang

telah rusak,maka direncanakan metode perbaikan dengan memperkuat struktur jembatan penyeberangan eksising dengan rencana gambar sebagai berikut :

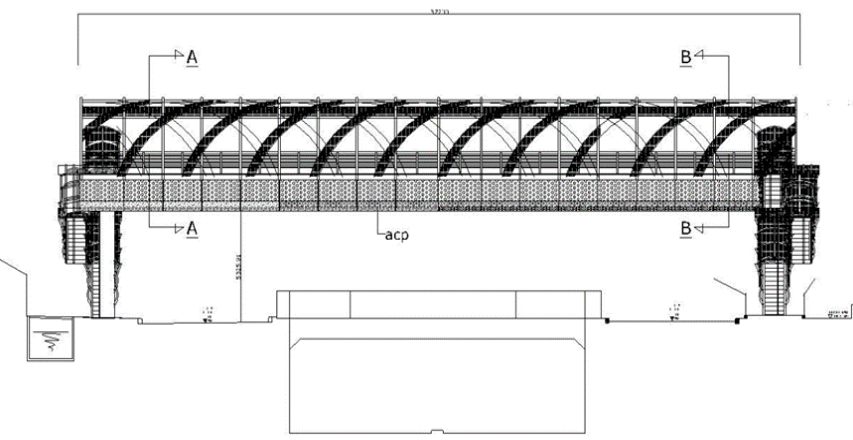

Gambar 4. Gambar Rencana Tampak Depan

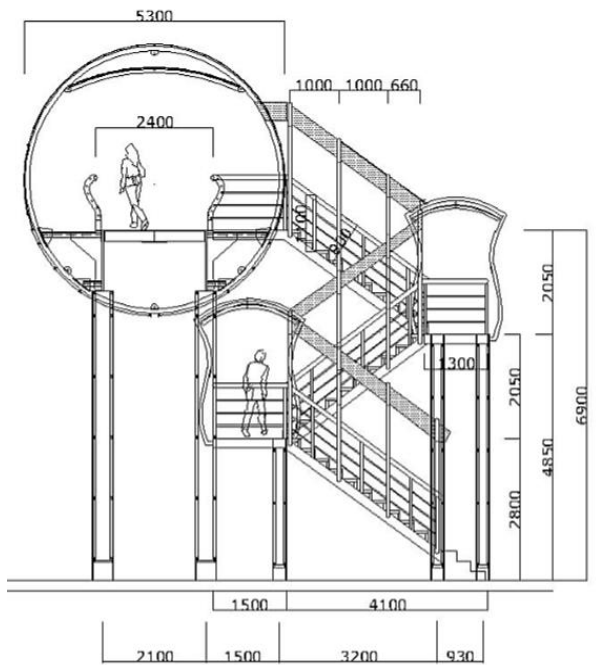

Gambar 5. Potongan A-A

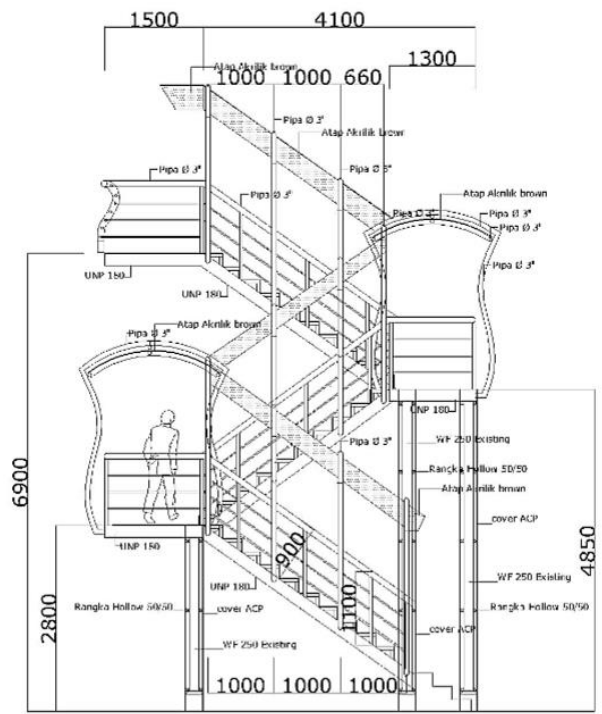

Gambar 6. Detail Tangga Tampak Samping

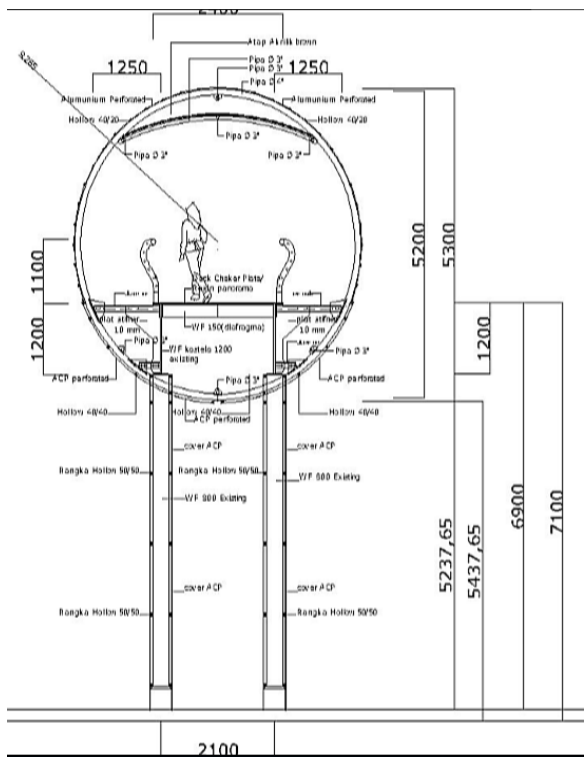

Gambar 7. Detail Silinder Jembatan 
Spesifikasi Jembatan Rencana :

- Waktu Pelaksanaan : 60 Hari Kalender

- Panjang jembatan $: 32,2 \mathrm{~m}$

- Lebar Jembatan : :5,3 m

- Tinggi jembatan dari permukaan jalan raya : $6,9 \mathrm{~m}$

\section{Metode Pelaksanaan}

\section{i. Pekerjaan Persiapan}

ii. Pembuatan base camp \& fasilitas proyek

iii. Pengukuran \& foto eksisting

iv. Kegiatan Engineering

v. Identifikasi,

dan

Metode yang digunakan untuk pelaksanaan pembangunan Jembatan Penyeberangan Orang di Stasiun Pasar Minggu ini adalah metode perancah dan metode peluncuran. Kontraktor harus menyiapkan dan menentukan titik pengukuran pada salah satu oprit jembatan yang cocok untuk merakit suatu rangka jangkar untuk pengimbang dimana pemasangan dengan cara perakitan bertahap akan dikerjakan, atau, bilamana pemasangan dengan cara peluncuran, struktur jembatan rangka baja yang telah lengkap bersama dengan struktur rangka pengimbang dan ujung peluncur.

Semua penyangga dan kumpulan balok-balok kayu sementara dan/atau pondasi beton yang disediakan oleh Kontraktor untuk pemasangan rol perakit, rol peluncuran, rol pendaratan atau jangkar dan penyangga struktur rangka jangkar harus ditentukan titik pengukurannya dengan akurat dan dipasang pada garis dan elevasi yang benar sebagaimana yang ditunjukkan dalam gambar pemasangan dari pabrik pembuatnya. Perhatian khusus harus diberikan untuk memastikan bahwa seluruh rol dan penyangga sementara terpasang pada elevasi yang benar agar sesuai dengan bidang peluncuran yang telah dihitung sebelumnya dan/atau karakteristik lendutan untuk panjang bentang jembatan yang akan dipasang.

1) Pemasangan Perancah

Untuk menopang beban yang akan berada diatas bidang eksisting maka digunakan perancah untuk menahan beban, dengan tetap memperhatikan posisi perancah tidak mengganggu aktivitas jalan raya di bawah jembatan.

2) Pemasangan Perletakan Jembatan

Perletakan jembatan dapat berupa jenis perletakan elastomerik atau perletakan sendi yang terpasang pada plat perletakan dan balok kisi-kisi. Tiap jenis perletakan harus dipasang pada elevasi dan posisi yang benar dan harus pada perletakan yang rata dan benar di atas seluruh bidang kontak. Untuk perletakan jembatan yang dipasang di atas adukan semen, tidak boleh terdapat beban apapun yang diletakkan di atas perletakan setelah adukan semen terpasang dalam periode paling sedikit 96 jam, perlengkapan yang memadai harus diberikan untuk menjaga agar adukan semen dapat dipelihara kelembabannya selama periode ini. Adukan semen harus terdiri dari satu bagian semen portland dan satu bagian pasir berbutir halus.

\section{3) Perakitan Komponen Baja}

Setelah semua perancah selesai dibuat dan berdiri pada posisi yang tepat, maka perakitan dapat dimulai. Perakitan dimulai dengan terlebih dahulu memilih semua komponen yang akan dirakit terlebih dahulu dan harus sesuai dengan gambar erection jembatan.

4) Pelaksanaan Peluncuran

Urutan pemasangan harus dilaksanakan dengan teliti sesuai dengan prosedur pemasangan yang diberikan dalam buku petunjuk dari pabrik pembuat jembatan. Kontraktor harus melaksanakan operasi pemasangan dengan memperhatikan seluruh ketentuan keselamatan umum dan harus memastikan bahwa struktur jembatan stabil dalam setiap tahap dalam proses pemasangan.

Untuk jembatan yang dipasang dengan prosedur peluncuran, Kontraktor harus mengambil seluruh langkah pengamanan yang diperlukan untuk memastikan bahwa selama seluruh tahap pemasangan struktur jembatan aman dari pergerakan bebas pada rol. Pergerakan melintasi rol selama operasi peluncuran harus dikendalikan setiap saat.

Seluruh bahan pengimbang (counter-weight) dan perancah sementara pekerjaan baja atau kayu untuk rangka pendukung pengimbang harus dipasok oleh Kontraktor. Beban pengimbang harus diletakkan dengan berat sedemikian rupa sehingga faktor keamanan untuk stabilitas yang benar seperti yang diasumsikan dalam perhitungan pemasangan dari pabrik pembuat jembatan dicapai pada tiap tahap perakitan dan pemasangan.

Operasi pemasangan dengan peluncuran atau perakitan bertahap harus dilaksanakan sampai struktur jembatan rangka baja terletak di atas lokasi perletakan akhir. Kontraktor kemudian harus memulai operasi 
pendongkrakan dengan menggunakan peralatan dongkrak hidrolik dan kerangka dongkrak yang disediakan oleh Pemilik. Struktur jembatan harus didongkrak sampai elevasi yang cukup untuk memungkinkan penyingkiran seluruh balol-balok kayu sementara, rol penyangga dan penyambung antar struktur rangka (link sets) sebelum diturunkan sampai kedudukan akhir jembatan.

\section{RENCANA ANGGARAN REKONSTRUKSI}

BIAYA

Estimasi biaya merupakan hal penting dalam dunia industri konstruksi. Ketidak-akuratan dalam estimasi dapat memberikan efek negatif pada seluruh proses konstruksi dan semua pihak yang terlibat.

Estimasi biaya konstruksi dikerjakan sebelum pelaksanaan fisik dilakukan dan memerlukan analisis detail dan kompilasi dokumen penawaran dan lainnya. Estimasi biaya mempunyai dampak pada kesuksesan proyek dan perusahaan. Keakuratan dalam estimasi biaya tergantung pada keahlian dan kerajinan estimator dalam mengikuti seluruh proses pekerjaan dan sesuai dengan infomasi terbaru. Secara umum komponen biaya yang tercantum dalam estimasi biaya konstruksi meliputi :

Material yang digunakan untuk merekonstruksi JPO Pasar minggu dihitung dan dianalisa pekerjaannya dengan melihat detail gambar rencana dan dihitung biayanya menggunakan referensi jurnal DKI Jakarta tahun 2017 yang dapat dilihat pada tabel berikut :

\begin{tabular}{|c|c|c|c|c|c|}
\hline No. & URAIAN & SAT. & VOL & $\begin{array}{c}\text { HARGA } \\
\text { SATUAN } \\
\text { (Rp) } \\
\end{array}$ & $\begin{array}{c}\text { JUMLAH } \\
\text { HARGA } \\
\text { (Rp) } \\
\end{array}$ \\
\hline A & PEKERJAAN BONGKARAN & & & & \\
\hline \multirow[t]{2}{*}{1} & Bongkar Kuda - Kuda Baja & $\mathrm{Kg}$ & $1,193.47$ & $6,648.90$ & $7,935,262.68$ \\
\hline & & & & TOTAL A & $7,935,262.68$ \\
\hline B & PEKERJAAN STRUKTUR BAJA & & & & \\
\hline 1 & Pekerjaan Pemasangan Pipa Baja & $\mathrm{Kg}$ & $11,798.51$ & $30,381.88$ & $358,460,849.07$ \\
\hline 2 & Pekerjaan Pemasangan Aluminium Composite Panel (Acp) & $\mathrm{m} 2$ & 460.89 & $1,159,639.15$ & $534,466,087.84$ \\
\hline 3 & Pekerjaan Pemasangan Besi Plat & $\mathrm{kg}$ & $1,974.90$ & $18,907.44$ & $37,340,342.96$ \\
\hline 4 & Pemasangan besi profil & $\mathrm{kg}$ & 3.929 .91 & $29,024.88$ & $114,065,310.12$ \\
\hline 5 & 1 Batang Pasang Pipa Baja (Tanpa Bahan) & btg & 118.00 & $14,079.00$ & $1,661,322.00$ \\
\hline \multirow[t]{3}{*}{6} & Tensile Membrane & $\mathrm{m} 2$ & 162.15 & $180,000.00$ & $29,187,000.00$ \\
\hline & Spesifikasi : Spesifikasi : Berat $850 \mathrm{Gsm} / \mathrm{M} 2$, Uk. $2,5 \times 70 \mathrm{M}$ & & & & \\
\hline & ( & & & TOTAL B & $1,045,993,911.99$ \\
\hline c & PEKERJAAN TAMBAHAN & & & & \\
\hline 1 & Pekerjaan Pengecatan Permukaan Pipa Baja & $\mathrm{m} 2$ & 414.06 & $158,639.46$ & $65,686,254.80$ \\
\hline & Pekerjaan Pengelasan Dengan Las Listrik & $\mathrm{cm}$ & $12,911.06$ & $3,885.14$ & $50,161,257.86$ \\
\hline \multirow[t]{7}{*}{3} & Pekerjaan Pengecatan Permukaan Plat Besi & $\mathrm{m} 2$ & 263.68 & $164,833.13$ & $43,462,547.63$ \\
\hline & & & & & \\
\hline & & & & TAL C & $159,310,060.29$ \\
\hline & & & & TTAL & $1,213,239,234.96$ \\
\hline & & & & $\sqrt{10 \%}$ & - \\
\hline & & & & ULAH & $1,213,239,234.96$ \\
\hline & & & & bulatan & $1,213,239,230.00$ \\
\hline
\end{tabular}

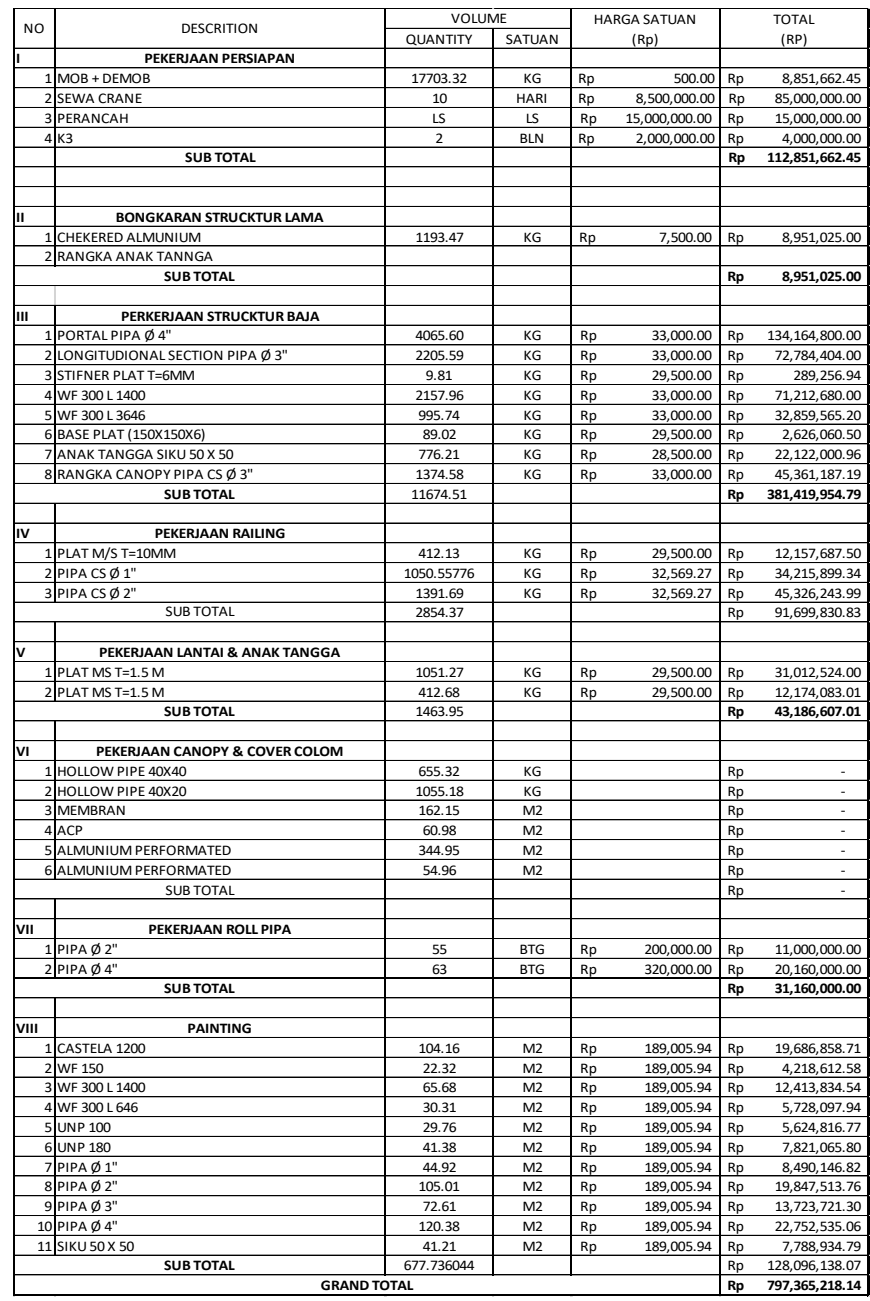

\section{KESIMPULAN}

Setelah melakukan perhitungan dan analisis terhadap proyek pembangunan Jembatan Penyeberangan Orang di Stasiun Pasar Minggu penulis menyimpulkan bahwa :

a. Kondisi jembatan eksisting masih dapat digunakan kembali tetapi dengan syarat diberi perlakuan perkuatan struktur.

b. Metode pelaksanaan yang diaplikasikan dalam membangun jembatan penyeberangan orang ini adalah metode perancah dan peluncuran dan dilakukan lebih banyak aktivitas di malam hari untuk menghindari kemacetan di jalan raya dibawah jembatan penyeberangan orang.

c. Biaya yang dibutuhkan untuk menyelesaikan proyek Jembatan Penyeberangan Orang di Stasiun Pasar Minggu ini adalah sebesar Rp 1.213.239.230 ( Satu milyar dua ratus tiga belas juta dua ratus tiga puluh sembilan ribu dua ratus tiga puluh rupiah) 


\section{REFERENSI}

Asiyanto. (2011). Metode Konstruksi Jembatan Rangka Baja. UI Press, Jakarta.

Anil K. Agrawal and Barney T. Martin Jr. (2017). Review of Inspection, Evaluation and Maintenance of Suspension Bridges, and Inspection, Evaluation and Maintenance of Suspension Bridges: Case Studies edited by Sreenivas Alampalli and William J. Moreau.Journal of Bridge Engineering, Vol.23,Issue4.

Ayu Pangestuti dan Dhian. (2015). Jembatan Struktur Rangka Baja (Steel Truss Bridge) Permodelan Jembatan Rangka "Dam Bridge". Jakarta : Bridge. Vol.2,No.2.

Badan Standardisasi Nasional., 2005. RSNI T02-2005 Tata Cara Perhitungan Untuk Jembatan. Jakarta: BSN.

Badan Standardisasi Nasional., 2005. RSNI T03-2005 Perencanaan Struktur Baja Untuk Jembatan. Jakarta: BSN.

Chen, W.,F. \& Duan, L. (1999). Structural Engineering Handbook. USA : CRC Press LLC.

Chen, W.,F. \& Duan, L. (2000). Bridge Engineering Handbook. USA : CRC Press LLC.

Chen, W.,F. \& Duan, L. (2003). The Civil Engineering Handbook Second Edition. USA : CRC Press LLC.

Direktorat Jenderal Binamarga. (1995). Tata Cara Perencanaan Jembatan Penyeberangan untuk Pejalan kaki di perkotaan, Departemen Pekerjaan Umum.

Departemen Pekerjaan Umum. (1995). Tata Cara Perencanaan Jembatan Penyeberangan Untuk Pejalan Kaki di Perkotaan. Jakarta.

Gunawan, R. (1987). Tabel Profil Konstruksi Baja.Yogyakarta: Penerbit Kanisius.

Hasan Busri. (2014). Analisis Alternatif Desain Bangunan Jembatan dengan Value Engineering.Surabaya: Jurnal Teknik Sipil.Vol.7 No.1, hal. 31-38.

L.T. Transport Ltd. (2004). Footbridges - A manual for Construction at Community and District Level. UK : Department for International Development.

Naiwei Lu and Mohammad Noori,. (2017). Fatigue Reliability Assessment of Welded Steel Bridge Decks under Stochastic Truck Loads via Machine Learning. Journal of Bridge Engineering, Vol.22,Issue 1.

Pedoman Perencanaan Jalur Pejalan Kaki pada Jalan Umum No.032/T/BM/1999, Kementrian Pekerjaan Umum.

Prisyafada, F.X. (2014). Perancangan Jembatan Hybrid Pejalan Kaki Kelas I Dengan Bentang Utama 80 meter.
Yogyakarta : Jurusan Teknik Sipil dan Lingkungan.

P.Dey and S.Narasimhan. (2017). Evaluation of Design Guidelines for the Serviceability Assessment of Pedestrian Bridges. Journal of Bridge Engineering, Vol.22,Issue 1.

Rudy Setiawan, ST., MT. (2006). Faktor- faktor yang mempengaruhi pemanfaatan jembatan penyeberangan, simposium IX FSTPT, Universitas Brawijaya, Fakultas Teknik Sipil \& Perencanaan Jurusan Teknik Sipil Universitas Kristen Petra, Surabaya.

Setiawan, A. (2008). Perencanaan Struktur Baja dengan Metode LRFD. Jakarta : Penerbit Erlangga.

Sukrawa Made. (2004). Buku Ajar Mata Kuliah Teknik Jembatan, Jurusan Teknik Sipil FT UNUD, Denpasar

Supriyadi, B. \& Muntohar, A.S. (2007). Jembatan. Yogyakarta : Beta Offset.

Tarigan, A.B., Perancangan Ulang Sambungan Baja Jembatan Gantung Pejalan Kaki Desa Kendalsari-Dompol, Klaten. Yogyakarta : Jurusan Teknik Sipil dan Lingkungan Fakultas Teknik Universitas Gadjah Mada.

United States Army's, Army Publishing Directorate., 2002. FM 3-34-343. United States Field Army Manuals for Fixed Bridging

Yudhistira, A.T. (2013). Evaluasi Kelayakan dan Fungsi Struktur Atas Jembatan Berdasarkan Nisai Sisa Kapasitas Jembatan. Yogyakarta : Jurusan Teknik Sipil dan Lingkungan Fakultas Teknik Universitas Gadjah Mada.

https://www.ilmutekniksipil.com/strukturjembatan-2/metode-pelaksanaanpekerjaan-konstruksi-jembatan ( diakses hari Kamis, 16 November 2017)

https://www.academia.edu/6947166/PEKERJAA N PERAKITAN JEMBATAN RANGKA BAJA (diakses hari Senin 11 Desember 2017)

Ilham, M Noer. (2011). Jenis Jembatan. http://mnoerilham.blogspot.co $\mathrm{m} /$. Diakses pada hari Jumat, 17 November 2017 pukul 20.43) 
Halaman ini sengaja dikosongkan 